\title{
Economism and ways to overcome it
}

\begin{abstract}
In the article "economism and ways to overcome it," at the center of e study is the ratio of the society, economy and the phenomenon of economism. It is proved thateconomism is related to mechanism, being its ontological, epistemological and methodological heir and social analogue. As an ideological phenomenon, mechanics perverts the philosophical picture of the world, and economism - a picture of the development of social being. Their relationship to the author sees in reductionism of the complex to the simple, the whole to the part. The methodological basis of the research is the principles of objectivity of being and its development, the unity of historical and logical, the opposition of positive and negative dialectics, ascent and degradation. The relevance of the study of the phenomenon of economism is due to the negative impact that it has on the development of modern man and mankind, giving rise to a transition from a positive dialectic of development, in which ascension prevails over descent, into a negative dialectic of degeneration, degradation, puts mankind on on the verge of extinction. It justifies the idea of the need to overcome it, as a phenomenon contrary to material being, its change and development. It reveals the essence of the universal nature of man as a social being, generated by being and its evolution, through which and in which the development of being is prolonged. Man does this in the course of that universal process of "production", which the ancient Greeks called the word "praxis". An important role in this process belongs to an economy designed to meet human needs, without which "production" is impossible. This process is stopped by economism. The article reveals the inadequacy of economism to the process of ascent from classical to post-non-classical, "human-dimensional" rationality, objective content, the dynamics of science and philosophy. Contradicting the ascending branch of social development, economism is a prerequisite for falling out of a positive dialectic into a negative one, which makes it necessary to substantiate its overcoming in theory and practice.
\end{abstract}

Keywords: picture of the world, mechanism, human nature, "production", society, economy, economism, development, degradation
Volume 2 Issue 6 - 2018

Mikhail M Prokhorov

Doctor of Philosophy, Nizhny Novgorod State University of Architecture and Construction, Russia

Correspondence: Mikhail M Prokhorov, Doctor of Philosophy, Professor of Department of History, Philosophy, Pedagogy and Psychology, Nizhny Novgorod State University of Architecture and Construction, Russia, Email mmpro@mail.ru

Received: February 05, 2018 | Published: December 31, 2018

\section{Introduction}

The purpose of the article is to study the phenomenon of economism, which the author distinguishes and contrasts with economics in the structure of society. According to T. Parsons, the society consists of several interacting subsystems - from culture, values, norms and patterns that regulate the actions and actions of people, the economy, whose main function is adaptation to the external environment, and the socio-political subsystem with the function of integrating society as a system. Analysis of society implies a transition from knowledge of self-regulating systems to self-developing "human-sized" systems. "The methodology of their research introduces the notions of "turning the possibility into reality", "target causality" and the development direction encompassing all levels of organization of matter in the "evolution of the main spheres of the Universe - nonliving nature, living nature and society". Such a paradigm is the core of the "research program". ${ }^{1}$ For specific sciences. Tsya it extends to the sphere of economy. It is contradicted by J. Gray's statement that "economic activity is not just different from all other manifestations of public life, but, moreover, conditions society as a whole, and sometimes dominates it". ${ }^{2}$ The author aims to explicate the content of the phenomenon of "economism", within which actually detects an excessive desire to determine the general public solely by economic factors, as opposed to the economy, which is understood as the fields and create wealth to meet human needs. J. Gray notes the dominance of the phenomenon of economism, still embedded in the mechanisms by which people produce and reproduce their material life. The article reveals the relationship of economism with mechanism and outlines ways to overcome it. The phenomenon of economism is considered in a specific sense, from the standpoint of Marxism, but not terminologically, but in fact, in fact, the problem. She $\mathrm{p}$ assmatrivaetsya Marx, involving the concept of the classical "political economy", which has been criticized to explicate itself Marxist $\mathrm{s}$ approach to the problem.A second proposed further development of the Marxist approach, taking into account occurred in the history, science and philosophy changes.

\section{Mechanism and his historical forms}

Mechanism is a worldview based on the idea that the mechanical form of movement is the only and the last objective and most fundamental reality, on the basis of and within which all that exists and can be explained. He "transfers" into mechanical notions not only the concepts of physics, chemistry and biology, depriving the corresponding phenomena of their specificity, but also philosophical categories (causality, interconnections, etc.), not taking into account the universal complexity of the movement and development of the material world and its phenomena. This was the "absolutization" of the laws of mechanics, into the scope of which all types of material movement were immersed (according to $\mathrm{H}$. Wolf, "the world is a machine", according to Lametri, man is a "man-machine"). It is unlawful to "reduce" complex phenomena, to reduce them to simpler forms. The first "historical form". ${ }^{1}$ Mechanism is generated by the consideration of motion as external to the unchanging, eternally selfidentical substance. The statements that cognizable objects may or may not be in motion are recognized as logically equal, although motion is 
the way being exists. At the same time, the endowment of matter with a movement by a supernatural beginning was asserted sophistically. J. Locke claimed that the movement of bodies emanates from God, that matter itself is a product of divine creation. Mechanism was confused in the disengagement of philosophers into materialists and idealists, as he introduced confusion in the interpretation of the relationship between philosophy and science. The definition of being as matter, in accordance with the division of philosophers into materialists and idealists, was given by V.I. Lenin, from whom the term acquired an adequate, philosophical, without confusion with natural science concepts, meaning. Overcoming the confusion of "scientific" and "philosophical" concepts was important "for understanding the essence of the main philosophical confrontations". ${ }^{3}$ For example, S. Clark (1675-1729) recognized the "materialistic" "cosmogonicmechanical naturalism": according to "the materialists, the structure of the Universe arose exclusively from the mechanical principles of matter and motion" in contrast to I. Newton's Mathematical Principles of Natural Philosophy, which I was unable to build a satisfactory model for the action of electromagnetic waves and the propagation of electromagnetic waves within the framework of the mechanism and justified the proposition that "the structure of the Sun and the planets can arise only through reasonable and free Pr rank". ${ }^{4}$ In the New Age, the existence of special types of fantasy "weightless" matter - caloric, luminous, electrical and magnetic fluids and equally imaginary natural simulacrum forces, and their connection with the studied body changes ("swimming force", "magnetic force", etc..). When it was discovered that the diverse natural forces and forms of energy are manifestations of the same single self-movement of matter (the law of conservation and transformation of energy), this form was overcome.

The second historical form of mechanism is connected with the understanding of motion only in the "narrowed" sense of the spatial movement of bodies, ignoring the infinity, universality, inexhaustibility of the world. Even when statements about motion as an attribute and mode of existence of matter (Toland, Golbach, Diderot) were made in philosophy, this meant simple mechanical movement, not change and interaction "in general," in all the richness of its inexhaustible manifestations. The third historical form of mechanism (preserved at the present time) is connected with the application of the reduction method of more complex forms of movement to simpler ones, when the multi-level nature of the internally contradictory nature of movement and the qualitative peculiarity of the laws of each level, not reducible to the laws of other levels of movement of existence, are ignored. "Part", one of the forms of the movement of matter, appeared as the whole in which everything "melted", replacing thephilosophical category of "matter". The "anthropo-social philosophy" of thinkers who sought to improve human society in accordance with the aspirations of the people who wrote P.A. did not fit into the hypostasis of mechanics. Holbach, "they take up arms in order to put an end to their sufferings, risking their lives". 5 According to V.N.Kuznetsov, "Holbach's anthropo-social philosophy rode to his materialistic" philosophy of nature ", but in essence was not (despite the appearances and statements of the author himself) its logically necessary consequence". ${ }^{3}$ Mechanism as a whole as a world-view paradigm was generated by the fact that mechanics was at one time the only science that received sufficient development and application in production, and seemed to be "science in general". In the history of the XVI-XVIII centuries, a mixture of "materialism" and "mechanism" arose, although manifestations of mechanism were also characteristic of idealist philosophers.

\section{Human versatility, "production", economics and econimism}

The world process generates a person in which and through which the world change continues. Hence, the essential characteristics of a person are the potential universality, infinity and universality, realized in the course of transforming the surrounding reality. Such a "production" is a "full development of a person's potential", "the development of all human abilities as an end in itself" or a development "without any predetermined measure" [2, p. 167]. It presupposes the "proportionality" of a person to all being, his movement, in the unity of variability and stability, and development, in which the tendency of ascent leads, as a leading one. "Production" refers to any activity that provides for self-realization of people, be it playing the flute, peach treat, arguing about Plato, a quick dance, giving a speech or organizing a celebration for the birth of children. Marx wrote about the essence of production as the essence of humanity. He did not mean that the essence of humanity consists in "filling sausages"; labor is an alienated, secondary form of what he called praxis. In ancient Greeks, the word praxis meant a kind of free, self-organizing activity, "through which we transform the world". ${ }^{2}$ The development of man as a social being and the progress of culture, inheriting the natural ascent to the mind and continuing it in the direction of greater humanity, is associated with resolving the contradiction between the potential universality of man and the actual limitation dictated by specific historical conditions, a certain era, a system of norms and values. This contradiction lies at the base of the activity. In the life of all society, the economy is designed to create conditions for the upward development, being associated with the universal dialectic of being and with the overcoming of all sorts of limitations. The place and role of a person is given by his generic essential universality, universality and infinity. Due to this, being preserves and continues its ascent, having its "continuation" in man. Otherwise, the economy would become a fundamental obstacle to the development of being, society, man and humanity. Such an obstacle is not the economy, but the phenomenon of economism, which predetermines the fallout from the positive dialectics, where progress dominates the regress, into the negative dialectic of degeneration. The dialectic of development makes it possible to identify the criterion of progressive development, its dominance over the manifestations of negative dialectics."Reformers" in post-Soviet Russia refused this criterion, which should be trusted to the economy and its dynamics, when they declared their famous: "We cannot choose between bad and good, we are forced to choose between bad and even worse", which predetermined the chosen strategy as a course of "survival", rather than the development of the country, society and each person as a subject (goals in themselves, according to I. Kant) and the development resource of the country and society, which have been neglected, putting in the forefront the interests of the oligarchs, in an alliance with logged in / ext officials came forward as they built the "vertical of power". It is not by chance that E. Gaidar in his work "The State and Evolution". 6 recognized only businessmen and officials as subjects of history who lead a "domination / subordination" struggle between them, and they recognized the other population as a "suffering category", "means of production ", Tools of labor. It's about not recognized as subject of history as a result of"economism" Gaidar. Forming in Russia "power vertical" has not made any fundamental changes lo. On its basis, the position of state officials began to strengthen, while E. Gaidar dreamed of "freeing business from power" (stated in the book's subtitle), weakening the state so that Adam 
Smith's famous hand "managed" everything so that everything was "submerged" into a market so that the market was not only an economy, but also a society being transformed into a mass consumer society. The society, of which the economy is a part, is "immersed" in the market as a whole, whose "logos" are clearly absolutized in the metaphor "The hands of Adam Smith. "Such a device implies social inequality between the rich and the poor, the "means of production". And after building the "power vertical", other segments of the population remained "means of production". This led to the revival of the state. ${ }^{7}$ Renewed the hateful people seeking to be subjects of history, the extreme socio-economic inequality, fixed in the years of Gaidar's "privatization" and continuing to this day due to retaining its position of "economism", when the labor of some people increases the profit and power of others "Ruling". "Economism" has gone beyond EFFECTS I have on the economy, affecting the society as a whole and its parts or spheres. Today, it is necessary to overcome "economism", return to the progressive course of reviving the true economy, which would contribute to resolving the above contradiction, moving society to a new level, bringing people closer to the "generic essence", in order to realize their ability to universality and universality, proportionality to being and its development. They only "produce it for real" when they do it freely, for their own sake, realizing the abilities of the "generic creature" and not in the form of coercion dictated by "unwillingness to starve". The contradictions of the contemporary Second Rossi and push to the key question: whether the country and its people need to scientists and thinkers "have advanced and substantiated options, scenarios, alternatives, prospects for future breakthrough, progressive, socially equitable development of Russian society and the Russian civilization, the Russian people, man, "or enough for them to" just comforted them, and urged them to be tolerant, to come to terms with an unjust, wild reality by taking action "from above" - from government, from poly tical and spiritual rulers and shepherds?". ${ }^{8}$ This is a question of priorities that also extend to the economic sphere, for man is the highest being for the economy. Society and the economy must be raised to this height, seeing in man a goal, and not a simple means for the evolution of an economy that is all-consuming. The forms that took processes in Russia, as well as the state of the economy, undermined by the impact of economism that strengthened its position, led to devastating consequences. This was a consequence of the crisis of power and spiritual "elites" inadequate to the people and the country, the elite "deadlock", "corruption", "at all levels and in all spheres". ${ }^{10}$ Russia needs an assembly of subjects of progressive development, in the context of which it must be "placed" for its development, and the economy. Economism is a brake on the economy, a successor and a social analogue of mechanism, distorting its beginning, hindering the development of the country. Its appearance corresponds to the spirit of the transition "from positivism to postmodernism," which relies on the hypostasis of the concepts of not the natural, but the humanities. In its most general form, economism is characterized by the fact that the whole diversity of phenomena associated with man and his existence "sinks" into the economy, as if the economy were not a party, a part of society, all social life, a social system, but this "universe" общественной жизни, который она подменяет и «подминает» под себя - как в механицизме механическая форма движения претендовала на подмену всех иных, более сложных форм движения материи; "Crush" them for themselves. So, in Russia, the spheres of education (regarded as a service sector), science (recognize the applied and deny the fundamental), art, medicine, management, and physical culture are immersed in the economy, as if they were not parts of society, of all social life, to which The economy is also concerned, but with parts of the economy hit by economism. K. Marx drew attention to the phenomenon of economism. He gave a critical analysis of anthropo-social philosophers and Classic second political economy and also laid the 1 bases overcome economism. ${ }^{11}$ are similar to e overcome mechanistic, but does not consolidate these views terminology. This was done in the context of the "philosophy of history". In 1845, he wrote that all former "philosophers only explained the world in various ways, but the point is to change it" ("Theses about Feuerbach"). And at this time, he in the most general form already knew what exactly was subject to change. This was clarified in the "Economic and Philosophical Manuscripts of 1844", which dealt with human history, which, in principle, had already been described by the classics of "political economy" by that time. They have already shown the "prison imprisonment", the "cave existence" of man in the world of economics, which, being a part of society, subordinated its power to it as a whole. The materialistic understanding of history was directed against this state. Marx. He was sure that economics is a necessary condition for life, because without an economic basis human life is impossible, as he was confident that the goal and purpose of human life does not lie at all in this necessary basis of life, which can and should be put in place parts of society so that it does not subjugate the life of society as a whole. It was at this point that Marx disagreed with the "political economists" who were positive about the domination of the part over the whole.

In the section "Wages," Marx shows that it is, firstly, determined by the hostile struggle between the capitalist and the worker. "According to political economists the interest of the worker is never opposed to the interest of society, whereas in reality the society is always and absolutely opposed to the interest of the worker", because he "owes his oppression to this society's order". On the contrary, "the interest of the capitalists... is hostile to the interest of the society", and this can only be mitigated, but not canceled by the "competition of capitalists". ${ }^{2}$ In this they saw the reasons for the defeat in such a war of those who are forced to sell their labor - and when the wealth of society progresses, and in times of crisis, when it "declines". The one who lives only by his work is not even considered by the classics of political economy as a person, distinguishing "between the work of a person with a machine and his work as a machine" (Marx quotes p. 69 of the work of V. Schultz "Movement of production. Historical and statistical study to substantiate the new science of state and society", published in 1843 in Zurich). ${ }^{12}$ They - "not the people, but only the means of production" (Marx quotes page 68-69 of the first volume. And works by E. Bure "On the poverty of the working classes in England and in France", published in Paris is, in the 1840 year). ${ }^{12}$ On page 74 E. Bure adds that "in the future life of nations, the blind forces of nature operating in machines will become our slaves and serfs". Marx writes this idea. ${ }^{12}$ This is the departure of a person from the sphere of production in the sense of alienated labor, the transition to technical means with artificial intelligence that implements the functions of creating the goods necessary for people, which were previously created with the direct participation of man. Now a person becomes "close" with such production, carried out with the participation of IT-technology. This is a qualitative change that coincides with the transition to communism. ${ }^{13}$ In the meantime, the owner, who buys labor at a price so low that it is barely enough for the worker to meet the most urgent needs, is not guilty of either insufficient wages or excessive work duration, because he himself obeys this "power of things". The emergence of the phenomenon of economism in ancient Greece was 
recorded by Aristotle, called "chrematistics". ON. Berdyaev wrote that mankind of the twentieth century still lives in the "economic century". ${ }^{14}$ Although man is a universal being, commensurate with being and his development, which appeared at the level of society. Arose at the turn of the X I of the X - the XX-th centuries Economism in Social-Democracy criticized VI Lenin, expressing his political essence with the thesis: "the workers are economic, the liberals are political struggle". ${ }^{15}$ (sounds quite modern - MP). He was against the "economic tasks of struggle" narrowed in the spirit of economism, since classes are not a purely economic phenomenon.

\section{Economism, science and philosophy}

The affirmation of human sociality as a universal being generated by the development of being, which led to the separation of society from nature and continuing its development in this new form of being of matter with domination of ascent over descent, degradation will inevitably lead to overcoming economism. In this sense, the coming revolution is the restoration and prolongation of the development of being, in which the economic sphere is called upon to create the necessary conditions, ensuring the human needs of people, if it is freed from economism. "P The policy-economy s" similarly entomologists studying $t$ any insects and positively relate to a society where "private interest" prevails, this is the "misfortune of society", the phenomenon of economism. Therefore K. Marx treated him "critically," negatively - with the aim and in search of overcoming the existing inhumanity in the future. Political economists position themselves simply as scientists who, according to E. Bure, study and describe how "industry became a war, and trade as a game", state that "the position of a worker in the face of who uses his work is not the position of a free seller ", because" the capitalist is always free to use labor, the worker is always forced to sell it ", that" in order for human life to be a commodity, slavery must be allowed ", that until now the industry was in a state of aggressive war," she squandered life The people who form its army are as cool as the great conquerors. The purpose of it was the possession of wealth, not the happiness of people. "Representatives of "economism" can be compared with historians studying the distant past, when literally slaves existed. We cannot, they say, like the hopes of L. Shestov, "the former to make unbecoming," but we simply study "what was", we reproduce it scientifically, we describe it. Here is a positivism. K. Marx takes a different position. ${ }^{16}$ Giving instead of superficially pragmatic, in the interests of the bourgeois, a universal, philosophical substantiation of economics. For him, philosophy is a "mirror" of the dialectic of the process of development, a way of self-consciousness of the "ascending subject of development". The philosopher puts on the court of the era the course of action and methods used by the ascending subject. Being generated by a social movement, philosophy represents this movement and extends its influence to the future. Its concrete generalization develops into a project of future development, a project of change of the world. It revives confidence, conviction of the subject of the development of being, being theoretical and practical, for its "method" is "social and political weapon". Marx also points to another pole, the thinking of whose representatives is determined by attempts to find refuge from objectivity in subtle subjectivity so as not to see one's future, which is determined by degeneration, negative dialectics.

He explores historical boundaries. the cave conditions of economism, the possibility of transition to the "kingdom of freedom", which "begins where work, dictated by need and external expediency, stops," concluding that "by the nature of things it lies on the other side of the sphere of material production". ${ }^{16}$ But not on the other side of the development of being. The first is relatively, transient, the second is absolutely, non-transient. He is looking for ways of reviving sociality in order to prolong the development of being, putting the development of the economy under the control of people, society, not to live in the "cave" of economism and not look at everything through bank notes (today - ruble, dollar or euro), but to appreciate everything according to its own characteristics and criteria. Consequently, Marxism does not approve materiality as the eternal domination of the economy, defeated and defeated by economism, as is often stated in the literature. On the contrary, it opens the limitations of economism opposed by economism. Consequently, it is not a statement of economism, but a search and invention of ways to overcome it. For this, it took comprehension of the essence of the economy, the discovery of the laws of its development. Therefore, to call such "economic" interests material in order to perpetuate them is tantamount to identifying mechanism with materialism. Economism obstructs being and development, as does mechanism. To debunk and overcome economism, like mechanism, it is necessary to counterpose it to the philosophical and scientific picture of the world, being and being. In the framework of the mechanistic picture, the world was likened to a clock, a mechanical device. In non-classical science, when mastering complex systems in technology and with the development of cybernetics in the middle of the 20th century, the world was likened to an organism, viewed as a process that eliminates "dead balance" and "predetermination ahead by established harmony" in the spirit of G. Leibniz. ${ }^{17}$ The world of objects began to be perceived on the basis of the ontology of complex self-regulating systems. ${ }^{1}$ The revision of the ontology of objects continued in post-non-classical science. From self-regulating systems moved to self-developing and, further, to the "human-sized ", including people, subjects, pursuing their own goals, for the realization of which they select certain means of achieving them. Classical and non-classical rationality does not lead us into the field of human activity, which has the goal of remaking reality. This distinguishes them from post-non-classical science, which deals with premeditated a change in the ontology of the object by man (instead of the "contemplating consciousness"). "The human action itself is not something external", but "is included in the system, changing each time the field of its possible states" ${ }^{18}$ The transition to the postnon-classics stage suggests the idea of "universal evolutionism", it "constitutes the conceptual core of the modern scientific picture of the world" and its "research program". ${ }^{2}$ They take both mechanism and economism beyond the boundaries, demanding to take into account that the properties of the economy as a subsystem of society are determined by a society consisting not only of economics.

When studying "human-sized" objects, the search for truth turns out to be associated with the statement of "humanistic values": "an objectively true explanation and description applied to" humansized" objects not only allows, but also assumes the inclusion of axiological factors in the explanatory provisions", as well as solving ethical, defining the boundaries of possible (and necessary! - MP) intervention" ${ }^{18,19}$ As can be seen, the norms and ideals of post-nonclassical science make it possible to overcome the depiction of a private, economic process that is universal in economism and open the possibility of representing the economy as a private manifestation of the general development of being and society. Well, if the "prehuman", devoid of reason matter still managed to ensure the priority of ascent over descent, overcoming the mechanism for which the supporters of mechanism were doomed, then for reasonable matter 
represented by opponents of economism, ensuring such a priority should be recognized as an ideal and normal. The "imprisonment" of mankind cannot last forever. It is necessary to free oneself from excessive "submission", "mediocrity" of a person (M. Heidegger), asserting "the subjectivity of the personality, in order to raise the individual-responsible way of life in the world to a historically significant value". ${ }^{20}$ This is the way to overcome economism, a form of alienation from sociality, as a result of which not only post-Soviet Russia, but all of humanity, the entire earthly civilization clearly embarked on the disastrous path of self-destruction. ${ }^{21}$ Overcoming economism will help to overcome the alienation from social reality in general and its development, as the overcoming of mechanismism has helped to overcome alienation from the whole of material reality and its movement.

\section{Conclusion}

The article contains a new interpretation of a number of wellknown philosophical positions, gives a comparative analysis of economism and mechanism, proves their ontological, gnoseological and methodological similarity - reductionism. Economism, like mechanism, reduces the complex to the simple, the highest to the lowest, seeks to plunge all phenomena of society into the economy, turning it into an all-consuming factor in relation to social reality. The author concludes that economism is the heir and the social analogue of mechanism. is he based on the provisions of the works of $\mathrm{K}$. Marx, V.I. Lenin, I. Kant, N.A. Berdyaev, K. Popper, V.S. Stepina, V.S. Semenova, E.T. Gaidar, N.G. Kozina and others. The failure of economism is justified by the advancement of man in modern society to the fore, whereby the subject of science becomes "human-sized" objects. Important for overcoming economism is the disclosure of its inadequacy to the objective content of science and philosophy, revealing the universality of human nature, commensurate with being and the unfolding process of ascent from classical to post-nonclassical, "human-sized" rationality in science and philosophy.

\section{Acknowledgment}

None.

\section{Conflicts of interest}

The author declares that there is no conflict of interest.

\section{References}

1. Stepin VS. Civilization and culture. SPb: SPbSU. 2011;407.

2. Eagleton T. Why Marx was right. Per from English. P Norvillo M: Career Press. 2013;304.
3. Kuznetsov VN. The problem of the meaning of the concepts "materialists" and "materialism" in modern European philosophy of the XVII-XVIII centuries. Historical and Philosophical Almanac. 2007;2:55

4. Leibniz GV. Works: In 4 tons. T1M. Thought. 1982;432-437.

5. Holbach PA. Selected Works: In 2 volumes. T1M: Thought. 1963;341.

6. Gaidar ET. How to separate property from power and improve the welfare of the Russians. $2^{\text {nd }}$ Edition. rev $\mathrm{SPb}$ : Norma. State and evolution. 1997;224.

7. Alekseev PV, Panin AV. Philosophy. Moscow: Moscow State University. 2014;384.

8. Semenov VS. The fate of philosophy in modern Russia. M: URSS. 2011.

9. Kozin NG. Does Russia have a future? Criticism of the historical experience of our time. M: Norma. 2008;464.

10. Maksimov VE. Self-destruction. M: Golos. 1995;352.

11. Prokhorov MM. A few thoughts on Marxist philosophy and modernity. Bulletin of the Russian Philosophical Society. 2010;4(56):87-91.

12. Marx K. Economic and philosophical manuscripts of 1844. In: Marx K, Engels F, Editors. From the early works. M: Politizdat. 1956;538:528529 .

13. Platonov S. After Communism: Book. Not intended for printing. $2^{\text {nd }}$ Edition. Second Coming: Conversations. M: Young Guard. 1991;556.

14. Berdyaev NA. Man and car. The problem of sociology and metaphysics technology. Problems of Philosophy. 1989;2:148.

15. Lenin VI. Pol collected cit. $5^{\text {th }}$ Edition. 1918;26;343-44.

16. Marx K Capital. In: Marx K, Engels F, Editors. Works Ed E2 T 25. Part II. $386-387$.

17. Wiener N. I am a mathematician. M: Nauka. 1964.314.

18. Stepin VS. Classics, non-classics, post-non-classics: criteria for distinguishing. Post-non-classics: philosophy, science, culture: Collective monograph. resp ed LP. Kiyaschenko and VS Stepin SPb: Publishing House "Mir". 2009;283.

19. Kopnin PV. Epistemological and logical foundations of science. M: Thought. 1974;568.

20. Huseynov AA. What did Kant say, or Why is it impossible to lie for good?. Logos. 2008;5:120.

21. Dubrovsky DI. The problem of virtuous deception. Kant and modernity. Questions of philosophy. 2010;1:31. 